REVISTA DE DERECHO UNED, NÚM. 8, 2011

\title{
EL DERECHO A LA INTIMIDAD DE LAS PERSONAS PRIVADAS DE LIBERTAD Y EL PRINCIPIO CELULAR A LA LUZ DE LA JURISPRUDENCIA CONSTITUCIONAL ${ }^{1}$
}

\author{
THE RIGHT TO INTIMACY OF STATE PRISON RESIDENTS AND \\ THE PRINCIPAL OF PRISON CELLS ACCORDING TO THE \\ CONSTITUTIONAL JURISPRUDENCE
}

\section{Juan Luis De Diego Arias}

\author{
Abogado \\ Profesor Asociado de Derecho Constitutional. UNED
}

Resumen: Análisis crítico de la Jurisprudencia del Tribunal Constitucional sobre el derecho a la intimidad de las personas privadas de libertad. Objeto y casuística de las Sentencias. Cuestiones abiertas: naturaleza del derecho a la intimidad de las personas privadas de libertad, comunicaciones especiales o "vis a vis», intimidad corporal, derecho subjetivo a un espacio individual.

Palabras clave: Prisión, intimidad.

Abstract: Critical analysis of the Constitutional Court Jurisprudence about the right to intimacy of State Prison Residents. Object and casuistry of Judgments. Subjects to be analyzed: nature of the right to intimacy of the persons deprived of freedom, special contacts or «vis to vis», corporal intimacy, civil right to an individual space.

Key words: Prison, privacy.

${ }^{1}$ Trabajo elaborado en el marco del Proyecto de Investigación del Ministerio de Ciencia e Innovación DER 2009-10375 sobre «Constitución y Globalización. Transformaciones del Estado Constitucional y constitucionalización de espacios supranacionales». Investigador principal: O. AlZAGa VILLAAmiL 
Nuestro Tribunal Constitucional ha dictado más de un centenar largo de sentencias sobre los derechos fundamentales de las personas privadas de libertad. La cifra puede parecer elevada, aunque se empequeñece si la ponemos en relación con el elevado número de personas que en la actualidad se encuentran internas en los centros penitenciarios, alrededor de setenta y seis mil ${ }^{2}$. Las razones de este escaso número de pronunciamientos no debemos querer buscarlo en la consideración de que el ámbito penitenciario sea un oasis de paz y ausencia de conflictividad, en el que se realizan las previsiones de nuestro artículo $25.2 \mathrm{CE}$, que señala la reeducación y la reinserción social como las orientaciones de las penas privativas de libertad y las medidas de seguridad. Quizá debamos hacerlo, como ha señalado un sector de la doctrina, en el hecho de que la mayor parte de los internos consideran inútil efectuar denuncia alguna de las malas prácticas penitenciarias, pues en la práctica sólo resultan condenados una minoría y en ocasiones la denuncia se vuelve en contra y perjudica a quien la formula ${ }^{3}$.

De todos los derechos que han sido objeto de estas Sentencias, vamos a centrar la atención en el derecho a la intimidad, uno de los más afectados por la reclusión. El propio Tribunal Constitucional ha puesto de manifiesto esta idea, al señalar que la afección que la reclusión conlleva en la intimidad, reducida casi al ámbito de la vida interior, es sin duda una de las consecuencias más dolorosas de esa privación apuntada, y que tanto es así que muchas de las actuaciones que de manera ordinaria se consideran privadas e íntimas, se encuentran no sólo expuestas al público, sino incluso necesitadas de autorización ${ }^{4}$. Dentro de este derecho queremos acotar un poco más el estudio y abordar el llamado principio celular, que consideramos una de las expresiones positivas del derecho a la intimidad de las personas privadas de libertad.

El derecho a la intimidad de las personas privadas de libertad ha sido estudiado en quince de esas sentencias por nuestro Alto Tribunal, desde la primera ocasión en que este fue alegado en este entorno opaco que suponen las relaciones de sujeción especial ${ }^{5}$, hace ya casi

${ }^{2}$ Un estudio de esta jurisprudencia puede verse en F. REviRIEGo PICÓN, Los derechos de los reclusos en la jurisprudencia constitucional, Universitas, Madrid, 2008.

${ }^{3}$ M. GALLEGo Díaz y otros: Andar $1 \mathrm{~km}$ en línea recta. La cárcel del siglo XXI que vive el preso. Universidad Pontificia de Comillas. Madrid 2010

${ }^{4}$ A título de ejemplo, puede verse la STC 57/1994, de 29 de febrero.

${ }^{5}$ Sobre las relaciones de sujeción especial puede verse LASAGABASTER HERRARTE, I., Las relaciones de sujeción especial, Cívitas, Madrid, 1994; LóPEz Benítez, M., Naturaleza y presupuestos constitucionales de las relaciones especiales de sujeción, Cívitas, 
un cuarto de siglo ${ }^{6}$. Sobre esta configuración apuntada, Cámara Villar señaló que se trata de una "categoría que hunde sus raíces en el seno de una estructura político-constitucional superada, que además no está jurídicamente definida en términos explícitos y cuyos contornos doctrinales, tanto en el plano jurisdiccional como en el científico, son ciertamente magros y evanescentes, por lo que se ha venido prestado sistemáticamente al abuso» ${ }^{7}$.

El objeto de los recursos ha sido, de manera principal o accesoria, pretendidas vulneraciones de la intimidad. En lo que a la resolución final del supuesto hace referencia, cuatro de las sentencias deniegan el amparo mientras que once lo otorgan, si bien entre estas últimas, cinco reconocen bien el derecho fundamental de defensa, bien el derecho fundamental a la tutela judicial efectiva, sin reconocer el de intimidad; sólo seis reconocen el derecho fundamental de la intimidad.

La casuística, dado el reducido número de pronunciamientos, ha sido muy limitada, siendo los cacheos con desnudo integral los que han acaparado mayor número de casos; hasta en cuatro ocasiones del total. La manipulación corporal con motivo de asistencia médica y la intervención de comunicaciones escritas han sido abordadas en dos ocasiones cada una de ellas; mientras que han sido objeto de una sola sentencia las comunicaciones especiales, la petición de celda individual, la intervención de comunicaciones, el uso del euskera en comunicaciones familiares, la visita de amigos y el registro en celda; una última planteaba unos hechos que poco o nada tenían que ver con la intimidad como luego veremos.

Dentro de la consolidada doctrina del Tribunal Constitucional sobre el derecho de intimidad de las personas privadas de libertad, destacan por reiteradas, dos de sus conclusiones: la calificación de la relación que se establece entre la persona privada de libertad y la Administración, por un lado, y la naturaleza de la intimidad en las prisiones, por otro.

La relación jurídica que se crea entre la persona privada de libertad y la Administración es incardinada por el Tribunal en las llama-

Madrid, 1994; GaRcía Macho, R., Las relaciones de especial sujeción en la Constitución Española, Tecnos, Madrid, 1992

${ }^{6}$ STC 89/1987, de 3 de junio.

7 «Relaciones de sujeción especial y derechos fundamentales», Derechos Constitucionales y Formas Políticas. Actas del congreso sobre derechos constitucionales y estado autonómico, Aparicio, M.A., (Coord.), Cedecs, Barcelona, 2001, pág. 117. 
das relaciones de sujeción especial, si bien en la Sentencia 89/2006 de 27 de marzo, el Tribunal Constitucional cambia la denominación de esta relación, cuando en vez de "relación de sujeción especial», habla de «intenso control público» ${ }^{8}$.

Por otro lado, ya en la primera sentencia sobre derecho de intimidad de las personas privadas de libertad, Sentencia 89/1987 de 3 de junio, aparece un argumento que se verá repetido con frecuencia en posteriores resoluciones y que ya hemos apuntado ut supra, esa casi «reducción» de lo íntimo al ámbito de la vida interior, la exposición de muchas actuaciones, también la necesidad de autorización de algunas, normalmente enmarcadas en lo que entendemos privado e íntimo.

$\mathrm{Al}$ no definir que es la vida interior nos quedamos sin saber a qué queda reducida la intimidad de las personas privadas de libertad. Parece aludir a la capacidad de introspección, de reflexión, de conciencia; las cuales facultan al individuo para abstraerse del exterior y le permiten habitar en un ensimismamiento que le aísla y le protege a la vez del mundo que le rodea; las facultades mencionadas -introspección, reflexión, conciencia- no se alcanzan espontáneamente, sino que requieren de un trabajo y adiestramiento continuado y generalmente muy dilatado en el tiempo. Si tenemos en cuenta que el perfil de la persona privada de libertad es una persona con bajo nivel educativo, carente de recursos económicos y socialmente marginado ${ }^{9}$, es muy difícil que pueda desarrollar esa vida interior que hemos designado. Si una persona privada de libertad no posee vida interior y la intimidad en prisión queda reducida casi a la misma, se puede preguntar ¿En qué consiste la intimidad para una persona privada de libertad? ¿Realmente gozará el condenado a prisión del derecho fundamental de intimidad que le reconoce el artículo $25 \mathrm{CE}$ ?.

La lectura de varias de las Sentencias nos ha planteado una serie de cuestiones que pasamos a enunciar siguiendo el orden cronológico de las resoluciones que las motivan y haciendo referencia a las mismas.

La Sentencia 89/1987 de 3 de junio es la primera que se pronuncia sobre el derecho a la intimidad de las personas privadas de libertad, siendo la que estrena el argumento de la reducción de la intimidad a la vida interior al que nos acabamos de referir.

Los hechos consistían en la denegación del disfrute de comunicaciones especiales. Comunicaciones especiales que se conocen por su

\footnotetext{
${ }^{8}$ STC 89/1986, de 27 de marzo (FJ $3^{\circ}$ ).

${ }^{9}$ M. Gallego y otros, op. cit.
} 
eventual contenido sexual, si bien no necesariamente tienen que consistir en una relación genital, pues es muy amplio el abanico de posibilidades de relación que se abre entre dos personas cuando gozan de un espacio reservado sólo para ellas.

Llaman la atención en el fundamento jurídico segundo, razonamientos en los que se distinguen «ejercicio de un derecho y manifestación de las actividades que hace posible la libertad» y llegar a la conclusión de que el mantenimiento de relaciones sexuales no forma parte del contenido de ningún derecho fundamental por ser una manifestación de la libertad a secas. ¿Existe entonces la libertad en abstracto, distinta de sus manifestaciones que son los actos libres? ¿Cómo resulta posible? En ese mismo fundamento se enuncia un problema, al que se le califica de complejo, pero al que se renuncia a entrar, y es este: «si la protección del ejercicio de libertades concretas implica sólo la obligación negativa del Estado o también la obligación positiva de dictar normas y adoptar las medidas oportunas para salvaguardar estas libertades en la relación recíproca entre los ciudadanos». Sería interesante profundizar en el mismo.

Sigue la sentencia declarando que «Lo que el Derecho protege es la intimidad misma, no las acciones privadas e íntimas de los hombres». Repetimos el mismo argumento que con la libertad y sus manifestaciones: ¿Existe la intimidad en abstracto? ¿Puede separarse la intimidad de los actos íntimos que son sus manifestaciones? ¿No sería más adecuado decir que el Derecho protege la intimidad de las acciones privadas e íntimas (valga la redundancia) de las personas?

La sentencia es ya antigua, casi un cuarto de siglo; la concepción de la sexualidad que en ella se mantiene probablemente era ya anticuada entonces y alejada de la vivencia común de la misma. Sin embargo lo que parece más llamativo es comprobar que se llega a unas conclusiones sobre la sexualidad sin apoyo alguno en las ciencias humanas que las pueden avalar; sin ningún fundamento estas alegaciones se convierten en meras opiniones del juzgador. Así se llega a conclusiones como las siguientes: «no se sigue que la abstinencia sexual resultado de la privación legal de libertad ponga en peligro la integridad física o moral del abstinente, tanto más cuanto se trata de una abstinencia temporal» $\mathrm{o}$ «la imposibilidad de mantener relaciones sexuales no implica tampoco la sumisión a un trato inhumano o degradante,» $\mathrm{O}$ «la privación de libertad, como preso o como penado, es sin duda un mal, pero de él forma parte, sin agravarlo de forma especial, la privación sexual» ¿Por qué la abstinencia sexual resultado de la privación legal de libertad no pone en peligro la integridad física o moral del abstinente? Y ¿Por qué esta abstinencia cuando es temporal 
es considerada un menor peligro para la integridad del abstinente? ¿Por qué no es considerada degradante la restricción o privación de las relaciones íntimas? ¿Por qué la privación sexual no agrava de forma especial el mal que supone la privación de libertad? ¿Por qué la autorización para la comunicación íntima que restaura circunstancialmente para el recluso un ámbito provisional de intimidad es el resultado de una concesión del legislador y no un imperativo derivado del derecho fundamental de la intimidad? ¿Qué concepción de la sexualidad hay detrás de esta afirmación?

En la Sentencia 120/1990, de 27 de junio, y en su fundamento jurídico cuarto aparece un razonamiento, en principio, contrario al de la anterior sentencia comentada; , se dice que «Es indudable que muchos de los derechos fundamentales y libertades públicas tutelables en amparo son proyecciones del valor libertad, pero sólo estas proyecciones concretas crean derechos amparables en esta vía procesal» Allí ,en la anterior sentencia, se decía en cambio que: «se distinguen ejercicio de un derecho y manifestación de las actividades que hace posible la libertad y llegar a la conclusión de que el mantenimiento de relaciones sexuales no forma parte del contenido de ningún derecho fundamental por ser una manifestación de la libertad a secas». Es decir, allí, una manifestación de la libertad a secas no forma parte del contenido de un derecho fundamental, y aquí, se mantiene que solo las proyecciones concretas del valor libertad crean derechos amparables. ¿Es una contradicción?

En la sentencia se sigue reflexionando, y sobre el artículo 9.2 de nuestra norma suprema apunta que» este precepto, al encomendar a los poderes públicos promover las condiciones para que la libertad y la igualdad del individuo y de los grupos en los que se integra sean reales y efectivas, remover los obstáculos que impiden o dificulten su plenitud y facilitar la participación de todos los ciudadanos en la vida política, económica, cultural y social, refleja la dimensión social del Estado de Derecho e impone determinados cometidos a sus poderes, pero no reconoce derecho subjetivo alguno que sea susceptible de protección de amparo. Si imponen determinados cometidos a sus poderes; ¿cuáles son estos y cómo se cumplen?

Interesantísimos nos parecen los votos particulares de los Sres. Rodríguez-Piñeiro y Leguina Villa pues plantean criterios interpretativos que se podrían tener en cuenta en otros enjuiciamientos sobre derechos de las personas privadas de libertad. Son estos: «¿Se habría otorgado el amparo si fuese un ciudadano en régimen de libertad?» y «se planteó desde el recluso que además está enfermo, cuando hubiese sido más correcto considerar al enfermo que además es recluso». 
A la doctrina de esta sentencia se remite expresamente la Sentencia 137/1990, de 19 de julio.

Los hechos de la Sentencia 57/1994, de 28 de febrero, consistieron por su parte en la negativa a hacer flexiones en un cacheo con desnudo integral tras una comunicación íntima.

En el fundamento jurídico cuarto se enuncia la naturaleza del derecho a la intimidad: «El derecho a la intimidad personal consagrado en el art. 18.1 aparece configurado como un derecho fundamental, estrictamente vinculado a la propia personalidad y que deriva, sin duda, de la dignidad de la persona humana que el art. 10.1 reconoce».

Después en el mismo fundamento define la intimidad personal que garantiza la Constitución: «la existencia de un ámbito propio y reservado frente a la acción y conocimiento de los demás, necesario -según las pautas de nuestra cultura- para mantener una calidad mínima de vida humana», haciendo referencia a la jurisprudencia constitucional $^{10}$.

Más adelante se aborda la intimidad corporal: «De la intimidad personal forma parte, según tiene declarado este Tribunal, la intimidad corporal frente a toda indagación o pesquisa que sobre el propio cuerpo quisiera imponerse contra la voluntad de la persona. Con lo que queda así protegido por el ordenamiento el sentimiento de pudor personal, en tanto responda a estimaciones y criterios arraigados en la cultura de la propia comunidad ${ }^{11}$. Volvemos a encontrar elementos sumamente interpretativos, se habla de sentimiento de pudor personal, pero algo tan subjetivo se valora en referencia a las estimaciones y criterios arraigados en la propia comunidad sin decir cuales son éstos y cómo se llega a la conclusión de que son esos. ¿Se puede objetivar lo que por naturaleza es subjetivo? Y ¿Una valoración con referencia a estimaciones y criterios no precisa de la fundamentación de por qué son esos los criterios y estimaciones y explicitar el método de porque se llega a esa conclusión?

Después se vuelve a objetivar la intimidad corporal, adjetivada de constitucionalmente protegida, diciendo que «no es una entidad física sino cultural y en consecuencia determinada por el criterio dominante en nuestra cultura sobre el recato corporal»; ¿Cuál es ese criterio y cómo se ha llegado a conocerlo? En la misma línea

\footnotetext{
${ }^{10}$ SSTC 231/1989, FJ 7; 120/1990 FJ 12, y 137/1990, FJ 10)

${ }^{11}$ SSTC 37/1989 FJ7, 120/1990 FJ12 y 137/1990 FJ10.
} 
interpretativa se puede leer más adelante que» según un sano criterio no son intromisiones forzadas en la intimidad aquellas actuaciones que, por las partes del cuerpo humano sobre las que se operan o por los instrumentos mediante los que se realiza no constituyen violación del pudor o recato de la persona»; ¿Cuáles son esas partes del cuerpo? ¿Cuáles esos instrumentos? ¿Cómo se objetiva algo tan subjetivo como el pudor y el recato?

La Sentencia 197/1994 de 4 de julio remite a los razonamientos en la STC 183/1994.

La Sentencia 195/1995 de 19 de diciembre estima parcialmente el amparo reconociendo el derecho a percibir una respuesta judicial motivada.

Se alega vulneración del derecho a la intimidad (art. 18.1 CE) por el hecho de que la Administración Penitenciaria le obligase a compartir su celda con otro recluso.

No se aprecia vulneración del derecho a la intimidad ya que, aunque el art. 19.1 de la Ley Orgánica General Penitenciaria y el art. 15 del Reglamento Penitenciario establecen con carácter general que cada interno ocupará una celda individual, también admiten la posibilidad de convivencia de varios internos en la misma celda por insuficiencia temporal de alojamiento u otras razones. Los citados preceptos de la legislación penitenciaria no consagran un derecho subjetivo a habitación o celda individual. Vuelve a repetir la reducción de la intimidad como consecuencia dolorosa de las personas que sufren privación de libertad en el ámbito penitenciario.

Sobre esta Sentencia volveré más adelante, al tratar del principio que es objeto de particular atención en este texto.

La Sentencia 128/1996 de 9 de julio estima parcialmente el amparo reconociendo el derecho de defensa y la tutela judicial efectiva.

Los hechos son un expediente disciplinario por subirse al tejado.

No se pronuncia sobre lesión del derecho de intimidad por su invocación inconsistente al no ofrecerse la más mínima explicación o fundamentación.

La Sentencia 200/1997 de 24 de noviembre desestima el recurso. Los hechos consistían en la intervención de las comunicaciones orales y escritas.

El secreto de las comunicaciones se considera como una concreción del genérico derecho a la intimidad. 
La Sentencia 201/1997 de 25 de noviembre otorga el amparo y reconoce el derecho a la intimidad familiar. La sentencia trajo como causa la prohibición de utilizar el euskera en las comunicaciones telefónicas con su familia.

Las Sentencias 128/1998 de 16 de junio y 229/1998 de 1 de diciembre otorgan el derecho al amparo reconociendo el derecho a la tutela judicial efectiva. La primera se refería a la prohibición de visitas de amigos, la segunda a la intervención de comunicaciones orales y escritas.

La Sentencia 204/2000 de 24 de julio estudia un caso de cacheo con desnudo integral y otorga el amparo reconociendo el derecho fundamental a la intimidad.

También a un cacheo con desnudo integral se refiere la Sentencia 218/2002 de 25 de noviembre. Otorga el amparo reconociendo el derecho a la intimidad personal y reitera la doctrina sobre la intimidad personal como un derecho fundamental, vinculado a la propia personalidad derivado de la dignidad humana y la concepción de la intimidad personal, constitucionalmente garantizada, como la existencia de un ámbito propio y reservado frente a la acción y el conocimiento de los demás, necesario -según las pautas de nuestra cultura- para mantener una calidad mínima de vida humana.

La Sentencia 89/2006 de 27 de marzo otorga el amparo. Reconociendo el derecho a la intimidad. Los hechos eran el registro en celda en ausencia de los ocupantes y sin entrega posterior de un acta del mismo.

Esta Sentencia resulta particularmente interesante pues aunque reitera la doctrina del Tribunal sobre la materia, introduce matices dignos de ser considerados:

Resalta la especial necesidad de preservar los ámbitos de intimidad no concernidos por la pena o la medida y por su ejecución, y de declarar ilegítimas como violación de la intimidad y por eso también degradantes, aquellas medidas que la reduzcan más allá de lo que la ordenada vida en prisión requiere.

Declara que es innegable que la celda es un ámbito de intimidad para su ocupante, un «espacio apto para desarrollar vida privada».

Esta es la sentencia donde la tradicional «relación especial de sujeción, se expresa de otra manera. Se apunta que el ingreso en prisión supone en consecuencia «la inserción del ciudadano en un ámbito de intenso control público». 
$\mathrm{Al}$ hablar de las limitaciones de los derechos fundamentales introduce el calificativo de «penitenciarias»; y lo explica diciendo que penitenciarias son las limitaciones anudadas a las propias de la institución penitenciaria.

Establece la relación entre el derecho a la intimidad y el conocimiento por su titular de que existe una injerencia en su ámbito de intimidad. No puede negarse la existencia de conexión entre la intimidad y el conocimiento de que la misma ha sido vulnerado y en qué medida lo ha sido.

Recuerda la íntima relación existente entre el derecho a la intimidad y la reserva de conocimiento. El derecho a la intimidad se traduce en «un poder de control sobre la publicidad de la información relativa a la persona y a su familia, con independencia de aquello que se desea mantener al abrigo del conocimiento público. El artículo $18.1 \mathrm{CE}$ garantiza al individuo un poder jurídico sobre la información relativa a su persona o a la de su familia, pudiendo imponer a terceros su voluntad de no dar a conocer dicha información o prohibiendo su difusión no consentida, lo que ha de encontrar sus límites, como es obvio en los restantes derechos fundamentales y bienes jurídicos constitucionalmente protegidos» (STC134/1999 de 15 de julio). Su devaluación es correlativa a la de la libertad, a la de la «calidad mínima de la vida humana» (STC 231/1988 de 2 de diciembre) que posibilita no solo el ámbito de intimidad sino el conocimiento cabal del mismo. Nos preguntamos si este extremo opera en el interior de las prisiones y si es así de que forma lo hace. ¿Cómo puede un interno imponer a sus compañeros su voluntad de no dar conocer la información sobre su persona o a la de su familia o prohibiendo su difusión no consentida?

Por último, en un contexto como el penitenciario, en el que la intimidad de los internos se ve necesariamente reducida por razones de organización y de seguridad, toda restricción añadida a la que ya comporta la vida en prisión debe ser justificada en orden a la preservación de un área de intimidad para el mantenimiento de una vida digna y para el desarrollo de la personalidad al que también le debe servir la pena como acertadamente señalara el artículo 25.2 de nuestro texto constitucional.

La Sentencia 196/2006 de 3 de julio otorga el amparo reconociendo el derecho a la intimidad. Los hechos son de nuevo un cacheo con desnudo integral.

Reitera la doctrina sobre la intimidad y presenta la peculiaridad de que se vincula el derecho a la intimidad corporal al principio de legalidad. 
El recurrente fue vulnerado en su derecho a la intimidad cuando se le sancionó por no haber accedido a un desnudo integral con el fin de suministrar una muestra de orina para control del consumo de sustancias tóxicas, control que dependía de la propia voluntad del recluso. El derecho a la intimidad corporal aparece aquí vinculado al principio de legalidad sancionadora del artículo 25.1 CE, por incluir entre los supuestos sancionables conductas calificadas como pertenecientes al ámbito de ejercicio de un derecho fundamental. Sobre la intimidad corporal, cabe recordar, como ha destacado Díaz Revorio, que tiene hoy unos perfiles bastante concretos; así, «en relación con otros sistemas, donde un derecho de contenido más amplio protege frente a todo tipo de intervenciones o indagaciones corporales, cabe destacar que en nuestro sistema la intimidad corporal tiene un contenido mucho más limitado» apuntando que «en general debe valorarse positivamente la labor realizada, que ha deslindado perfectamente este derecho de la integridad física, señalando con claridad los requisitos para la legitimidad de las intervenciones» ${ }^{12}$.

Después de este breve recorrido por las Sentencias que se pronuncian sobre el derecho a la intimidad de las personas privadas de libertad, parece oportuno recapitular las cuestiones planteadas que por otro lado nos dejan abiertos algunos interrogantes.

Si una persona privada de libertad no posee vida interior y la intimidad en prisión queda reducida casi a la misma, se puede preguntar ¿En qué consiste la intimidad para una persona privada de libertad? ¿Realmente gozará el condenado a prisión del derecho fundamental de intimidad que le reconoce el artículo $25 \mathrm{CE}$ ?

$¿$ Existe la libertad en abstracto, distinta de sus manifestaciones que son los actos libres?

¿La protección del ejercicio de libertades concretas implica sólo la obligación negativa del Estado o también la obligación positiva de dictar normas y adoptar las medidas oportunas para salvaguardar estas libertades en la relación recíproca entre los ciudadanos? Si imponen determinados cometidos a sus poderes; ¿cuáles son estos y cómo se cumplen?

¿Existe la intimidad en abstracto? ¿Puede separarse la intimidad de los actos íntimos que son sus manifestaciones?

12 "La Intimidad corporal en la jurisprudencia constitucional», Cuadernos Constitucionales de la Cátedra Fadrique Furió Ceriol, no 20/21,1997. 
¿Por qué la abstinencia sexual resultado de la privación legal de libertad no pone en peligro la integridad física o moral del abstinente? Y ¿Por qué esta abstinencia cuando es temporal es considerada un menor peligro la integridad del abstinente?

¿Por qué no es considerada degradante la restricción o privación de las relaciones íntimas? ¿Por qué la privación sexual no agrava de forma especial el mal que supone la privación de libertad?

¿Por qué la autorización para la comunicación íntima que restaura circunstancialmente para el recluso un ámbito provisional de intimidad es el resultado de una concesión del legislador y no un imperativo derivado del derecho fundamental de la intimidad? ¿Qué concepción de la sexualidad hay detrás de esta afirmación?

¿Por qué algo tan subjetivo como el sentimiento de pudor personal se valora en referencia a las estimaciones y criterios arraigados en la propia comunidad sin decir cuáles son estos? ¿Se puede objetivar lo que por naturaleza es subjetivo?

¿Una valoración que hace referencia a estimaciones y criterios precisa de fundamentación de por qué son esos los criterios y estimaciones? Y ¿Dicha valoración debe explicitar el método por el que se ha llegado a esa conclusión?

$\mathrm{Si}$, según un sano criterio no son intromisiones forzadas en la intimidad aquellas actuaciones que, por las partes del cuerpo humano sobre las que se operan o por los instrumentos mediante los que se realiza no constituyen violación del pudor o recato de la persona»; ¿Cuáles son esas partes del cuerpo? ¿Cuáles esos instrumentos?

Si el artículo 18.1 CE garantiza al individuo un poder jurídico sobre la información relativa a su persona o a la de su familia, pudiendo imponer a terceros su voluntad de no dar a conocer dicha información o prohibiendo su difusión no consentida, ¿Cómo se garantiza este poder en el interior de las prisiones? ¿Cómo puede un interno imponer a sus compañeros su voluntad de no dar conocer la información sobre su persona o a la de su familia o prohibiendo su difusión no consentida?

Una vez hecha referencia a cada una de las Sentencias del Tribunal Constitucional, en materia de derecho a la intimidad de personas privadas de libertad, quiero llamar la atención sobre el siguiente extremo: de las sentencias estudiadas, todas ellas, salvo una, tienen como objeto la intimidad en sentido negativo, es decir actuaciones que supuestamente atentan contra el derecho de la intimidad. Recordemos que estos presuntos atentados consistían en denegación o 
intervención de comunicaciones, manipulación corporal con motivo de asistencia médica, cacheos con desnudo integral y registro en celda. Sólo una de ellas, tiene por objeto la intimidad en sentido positivo, donde un interno alega su derecho a habitación o celda individual. Ésta es la Sentencia 195/1995, llamada Sentencia del principio celular.

En la demanda que motivó la Sentencia 195/1995 de 19 de diciembre se denunciaron como vulnerados el derecho a la intimidad y a la tutela judicial efectiva, consagrados respectivamente en los artículos 18.1 y 24.1 de la Constitución. El primero de ellos se habría vulnerado al infringir el Centro Penitenciario lo dispuesto en el artículo 15 del Reglamento Penitenciario que prescribe con carácter general que los internos ocuparán celda o habitación individual.

El Fiscal respecto a la denunciada vulneración del artículo 18.1 de la Constitución estimó que la convivencia de dos internos en la misma celda no afectaba al contenido del derecho a la intimidad, pues el párrafo segundo del art. 15 del Reglamento autoriza tal convivencia cuando exista una causa que la justifique, como puede ser la insuficiencia temporal de alojamiento; debiéndose además la protesta del interno no al hecho de compartir su celda, sino de compartirla con persona desconocida. Dos comentarios nos suscitan los argumentos del Ministerio Fiscal: Primero: el artículo 15 del Reglamento penitenciario efectivamente autoriza la convivencia en celda pero nada dice de la intimidad, por lo que mal puede fundamentarse en él, la no afectación del contenido del derecho a la intimidad. Segundo: tampoco nos parece puede ser fundamento de la no afectación de la intimidad el hecho de que el interno protestase por compartir su celda con persona desconocida, pues es precisamente la presencia de personas desconocidas la que amenaza la intimidad. Una de las manifestaciones de la intimidad es el espacio íntimo compartido voluntariamente por dos o más personas, pasando de ser una intimidad personal a una intimidad común. Quizás sea esta una manifestación más de lo que hemos dado en llamar intimidad positiva, el que dos o más personas por vínculos de distinta naturaleza deciden reservar su espacio común sólo para ellos.

El Abogado del Estado, por su parte, se pronunció en el sentido de que ni del artículo 15 ni mucho menos aún del 18.1 C.E. dimana el derecho de las reclamaciones de carácter fundamental, ya a impedir que se habilite una habitación colectiva, ya a negarse a compartir la celda con otro recluso. 
La Sentencia, en lo referente a la celda individual, denegó la existencia de un derecho a la misma, fundamentando su fallo en los siguientes argumentos:

El primer argumento es que «no puede apreciarse la denunciada vulneración del derecho a la intimidad (artículo 18.1 CE), pues si bien es cierto que tanto el artículo 19.1 de la Ley Orgánica General Penitenciaria como el artículo 15 del reglamento penitenciario establecen con carácter general que cada interno ocupará una celda individual, asimismo admiten la posibilidad de convivencia de varios internos en la misma celda por insuficiencia temporal de alojamiento u otras razones, sin que por ello hayan de considerarse vulnerados los mencionados preceptos de la legislación penitenciaria, que no consagran un derecho subjetivo a la habitación o celda individual». Es decir, parece que fundamenta la no vulneración de la intimidad en que los artículos citados de la legislación penitenciaria no establecen un derecho subjetivo a la celda individual; pero de la inexistencia de este derecho subjetivo no se puede deducir si la intimidad ha sido o no vulnerada.

En segundo lugar, la sentencia reproduce el argumento de la reducción de la intimidad en el ámbito de la prisión, añadiendo una reflexión de difícil entendimiento; en este sentido dice: Tal derecho tampoco puede extraerse directamente del artículo 18.1 CE pues una de las consecuencias más dolorosas de la privación de libertad es la reducción de la intimidad de quienes la sufren, de tal manera que sólo podrán ser consideradas lesivas de la intimidad aquellas medidas que la reduzcan más allá de lo que la ordenada vida en prisión requiera, requisito que no concurre en el presente caso pues, como ya se ha puesto de manifiesto, la propia legislación penitenciaria prevé en determinados supuestos la posibilidad de celdas compartidas.» No se entiende muy bien porque llega el Tribunal a estas conclusiones. Afirma que son lesivas de la intimidad las medidas que la reduzcan más allá de lo que requiera una vida en prisión ordenada, añadiendo después que la legislación penitenciaria prevé la posibilidad de celdas compartidas. Creo que nada tiene que ver la previsión de celdas compartidas con un mayor orden, pues parece evidente que un mayor orden se consigue con las celdas individuales. El artículo 15 del Reglamento Penitenciario no parece referirse ni al orden a la prisión ni a la intimidad en las celdas, por lo que no puede utilizarse para un razonamiento en este sentido. Que compartir celda es lesivo para la intimidad es una evidencia incontestable. El artículo del reglamento penitenciario establece una excepción al régimen general del principio celular, nada dice ni de la intimidad ni del orden en la 
prisión. El principio celular no solo no afecta a una ordenada vida en prisión, sino que colabora a ese orden.

Esta Sentencia me hace plantearme si el derecho a la intimidad tiene en su contenido mínimo la existencia de un espacio reservado sólo para la persona.

Varios autores han llevado su atención a esta sentencia y al principio celular. Luis E. Delgado del Rincón ha dicho que la previsión legal del principio celular tiene por finalidad facilitar a los internos un espacio físico, aunque sea mínimo, para que, en algunos momentos del día, éstos puedan aislarse en su celda de los demás reclusos, disfrutando de una mayor intimidad de la que tendrían en dependencias colectivas. De ahí que la celda se convierta en el reducto principal de la intimidad de los presos. Asimismo, este principio encuentra su fundamento en la necesidad de respetar la personalidad y la dignidad humana de los reclusos ${ }^{13}$. Se podría añadir que de ese respeto a la personalidad y de esa dignidad humana deriva el propio derecho a la intimidad.

La cuestión que cabe plantearse en este momento es si el alojamiento en celda individual constituye un derecho del preso y si este derecho forma parte integrante del contenido del derecho a la intimidad personal. Dicho de otra manera si el hecho de que la Administración Penitenciaria obligue a un preso a compartir celda con otros, fuera de los casos previstos en la legislación penitenciaria, vulnera su derecho a la intimidad personal.

Debido a la situación real de masificación en la que se encuentran la mayor parte de nuestros establecimientos penitenciarios, lo que debería ser excepcional, el alojamiento de los reclusos, pasa a ser la regla general. En esta situación «la insuficiencia temporal de alojamiento» se convierte en permanente y constituye motivo legal para que la Administración penitenciaria justifique siempre el alojamiento en celda colectiva de los reclusos, vaciando en la práctica, el contenido del principio celular o de alojamiento en celda individual que la ley atribuye al preso.

Para Subijana Zunzunegui «si el núcleo básico del derecho fundamental a la intimidad personal viene constituido por la presencia de un ámbito vital propio reservado al conocimiento y acción de los

13 «Algunas consideraciones sobre el derecho a la intimidad personal y familiar de los presos en los centros penitenciarios», Teoría y Realidad Constitucional, $\mathrm{n}^{\circ} 18$, 2006. 
demás, resulta discutible no percibir una injerencia en el mentado ámbito cuando se obliga a una persona a compartir con otra u otras el espacio físico en el que se desarrollan los actos vitales más específicamente más personales ${ }^{14}$.

Para otro sector doctrinal la argumentación del Tribunal en este punto, adolece de un esfuerzo teorizador sobre la eventual emergencia de este derecho subjetivo de las propias previsiones del artículo 18 de nuestra norma suprema. Por más, como se apunta, el resultado final sería exactamente el mismo: inexistencia de tal derecho.

Duque Villanueva al reflexionar sobre la existencia de un derecho subjetivo a la celda individual dice que "al igual que no cabe inferir del contenido del derecho a la intimidad o de la garantía de inviolabilidad del domicilio el derecho a poseer o disfrutar de un domicilio o espacio físico en el que desenvolver la vida privada y familiar, tampoco creo que pueda inferirse como contenido del citado derecho fundamental en el ámbito penitenciario el derecho de los internos a alojarse en celdas individuales» ${ }^{15}$. Y en cambio, añadimos nosotros, los precedentes del derecho de la intimidad se han situado por la doctrina en los primeros reconocimientos de la inviolabilidad del domicilio, como si intimidad y domicilio formaran una unidad.

La analogía que utiliza Duque Villanueva nos hace recordar con pesar, que a día de hoy, el derecho a una vivienda digna, que es el espacio apropiado para desarrollar la vida íntima, no sea todavía un derecho subjetivo. En nuestra Constitución existen toda una galería de principios rectores de la política social y económica que pueden, de momento, no crear derechos subjetivos, pero que constituyen el horizonte al que una sociedad debe caminar cuando, como en nuestro caso se propone como meta una democracia avanzada, la justicia y la igualdad. Una cosa es declarar derechos subjetivos y otra muy distinta que el Estado se quede sin recursos para corregir las actuaciones que no sólo no nos llevan al objetivo marcado sino que nos orientan en dirección contraria. Si nos fijamos en la vivienda, aceptando que de momento no es un derecho subjetivo, ¿Se puede permanecer inactivo cuando hemos asistido a toda una década de especulación inmobiliaria que ha convertido la vivienda no ya en un derecho sino en

14 «Los derechos fundamentales de las personas privadas de libertad y la doctrina del Tribunal Constitucional», Cuaderno del Instituto Vasco de Criminología, n ${ }^{\circ} 12$, 1998.

15 «El derecho a la intimidad personal y familiar en el ámbito penitenciario», Perfiles del derecho constitucional a la vida privada y familiar, Cuadernos de Derecho Judicial, Madrid, 1996. 
un lujo? Una vez más reitero el interés de profundizar en esta cuestión. Derecho subjetivo es aquel que se puede reclamar jurídicamente. La existencia del mismo depende del reconocimiento que el derecho positivo haga del mismo. Muchos de los derechos han nacido por la evolución del pensamiento social que una vez madurado y consolidado recibe de la ley el espaldarazo jurídico definitivo. Los ejemplos son muchos, quedémonos con el derecho a contraer matrimonio de las parejas del mismo sexo, o el derecho a la salud reflejado en las leyes que propician un espacio libre de los humos del tabaco.

Por último un sector de la doctrina ha vuelto a incidir sobre la «cicatera» argumentación del Tribunal Constitucional diciendo que «no parece que pueda despacharse con tanta facilidad la importante afección a la intimidad del interno que ello conlleva, y que no parece ser consecuencia ineludible de la reclusión ${ }^{16}$.

Es verdad que cuesta aceptar esta pobreza de argumentos cuando lo que está en juego son derechos fundamentales de un parte de la población, especialmente frágil y para la cual nuestra Constitución establece un cuidado especial en aras de su recuperación para la sociedad.

Sería de sumo interés estudiar la «ratio legis» del artículo 19.1 de la Ley Orgánica Penitenciaria y del artículo 15 del Reglamento Penitenciario; y llegar a saber si el principio celular obedece a preservar un espacio íntimo para la persona privada de libertad o, si además la celda individual es el ámbito espacial adecuado para alcanzar la rehabilitación y reinserción social. Si en nuestro sistema penitenciario tal y como lo declara la Constitución en su artículo 25, todo debe estar orientado a la rehabilitación y reinserción social, nos preguntamos si un espacio individualizado y reservado resulta necesario para que la persona pueda realizar el proceso de introspección preciso para asimilar unos nuevos valores que le permitan volver a la vida exterior como un ciudadano responsable. Esta es la reflexión que se me ocurre en cuanto a la necesidad de la celda individual como espacio para la reflexión, indispensable para que cualquier ser humano tome conciencia de su ser, pueda hacerse señor de sus pensamientos, afectos y emociones y tras un proceso de asimilación y reflexión estar en las condiciones de optar por el sistema de valores que la sociedad se ha dado a si misma para llevar una vida ordenada y pacífica.

${ }^{16}$ Reviriego Picón, F., Los derechos de los reclusos en la jurisprudencia constitucional, cit. 
La segunda cuestión, al albur del principio celular y del debate sobre la existencia de un derecho subjetivo a un espacio individual y reservado, es extrapolar la cuestión del ámbito penitenciario y hacerla general. Es decir si existe un derecho universal a un mínimo espacio reservado que preserve la intimidad. Se nos vienen a la mente las habitaciones de nuestros hospitales, de nuestras residencias, donde las personas comparten espacio, donde una persona debe realizar actos íntimos en presencia de otros, donde recibe las visitas de su personas íntimas, donde se enfrenta al acto definitivo y personalísimo de la propia muerte. ¿No tiene toda persona el derecho a un mínimo espacio reservado para sí y para las personas con las que decida compartir su intimidad?. Es más ¿No existe un derecho a la intimidad pasivo?, es decir ¿Estamos obligados a presenciar el proceso morboso de otro, sus actos íntimos, las visitas de sus familiares, su muerte?

Las habitaciones compartidas, las celdas compartidas deberían ser voluntarias cuando entre las personas que quieren ocuparla se ha creado un vínculo afectivo, bien de pareja, bien de amistad, bien de familia. En el ámbito específico de las prisiones habría que averiguar si la posibilidad de celdas compartidas para internos que compartan intimidad sería compatible con la ratio legis del principio celular; es decir si además de la necesidad de intimidad, el principio celular está orientado a la soledad necesaria para un proceso de rehabilitación, en este caso la celda compartida no sería conveniente.

La Sentencia 89/2006 de 27 de marzo que otorgó el amparo, reconociendo el derecho a la intimidad puede proporcionar argumentos y criterios para profundizar en la esencia del derecho de intimidad. Recordemos que allí los hechos eran el registro en celda en ausencia de los ocupantes y sin entrega posterior de un acta del mismo.

Lo primero que llama la atención es que vincula intimidad a celda cuando declara que «es innegable que la celda es un ámbito de intimidad para su ocupante, un espacio apto para desarrollar vida privada». Esta vinculación vuelve a aparecer cuando relaciona el derecho a la intimidad con el conocimiento por su titular de que existe una injerencia en su ámbito de intimidad, siendo la celda el ámbito de intimidad al que se refiere.

Sigue diciendo que el ámbito de intimidad posibilita una «calidad mínima de la vida humana» y que «toda restricción añadida a la que ya comporta la vida en prisión debe ser justificada en orden a la preservación de un área de intimidad para el mantenimiento de una vida digna y para el desarrollo de la personalidad al que también le debe servir la pena». Se podría pensar que se vincula la celda indivi- 
dual a una calidad mínima de vida humana y a la preservación de un área de intimidad.

La Sentencia niega la analogía de la celda con el domicilio; conclusión evidente que no necesita de mucha explicación. No obstante para diferenciar celda de domicilio emplea un argumento que además de innecesario parece no ser muy real, pues afirma que la celda contrariamente al domicilio no reúne las características de haber sido objeto de elección; cabe preguntarse cuanto margen de elección de domicilio hemos tenido muchas personas para elegir domicilio.

¿Cuál es el límite en la reducción de la intimidad para que éste derecho sea identificable, protegiéndose su contenido mínimo?

La intimidad queda reducida por las exigencias de las medidas de una ordenada vida en prisión. ¿Qué es una ordenada vida en prisión?

¿Tiene el derecho a la intimidad en su contenido mínimo la existencia de un espacio reservado sólo para la persona?

$\mathrm{Al}$ igual que al finalizar el recorrido por las Sentencias del derecho a la intimidad de las personas privadas de libertad, concluimos ahora señalando las cuestiones que se han ido planteando con motivo del principio celular.

El artículo 15 del Reglamento penitenciario autoriza la convivencia en celda pero nada dice de la intimidad, por lo que mal puede fundamentarse en él, la no afectación del contenido del derecho a la intimidad.

Una de las manifestaciones de la intimidad es el espacio íntimo compartido voluntariamente por dos o más personas, pasando de ser una intimidad personal a una intimidad común. Quizás sea esta una manifestación más de lo que hemos dado en llamar intimidad positiva, el que dos o más personas por vínculos de distinta naturaleza deciden reservar su espacio común sólo para ellos.

La Sentencia parece que fundamenta la no vulneración de la intimidad en que los artículos citados de la legislación penitenciaria no establecen un derecho subjetivo a la celda individual; pero de la inexistencia de este derecho subjetivo no se puede deducir si la intimidad ha sido o no vulnerada.

No se entiende muy bien porque llega el Tribunal a ciertas conclusiones. Afirma que son lesivas de la intimidad las medidas que la reduzcan más allá de lo que requiera una vida en prisión ordenada, 
añadiendo después que la legislación penitenciaria prevé la posibilidad de celdas compartidas. Creo que nada tiene que ver la previsión de celda compartidas con un mayor orden, pues parece evidente que un mayor orden se consigue con las celdas individuales. El artículo 15 del Reglamento Penitenciario no parece referirse ni al orden a la prisión ni a la intimidad en las celdas, por lo que no puede utilizarse para un razonamiento en este sentido. Que compartir celda es lesivo para la intimidad es una evidencia incontestable. El artículo del reglamento penitenciario establece una excepción al régimen general del principio celular, nada dice ni de la intimidad ni del orden en la prisión.

¿Tiene el derecho a la intimidad en su contenido mínimo la existencia de un espacio reservado sólo para la persona?

El principio celular encuentra su fundamento en la necesidad de respetar la personalidad y la dignidad humana de los reclusos. Se podría añadir que de ese respeto a la personalidad y de esa dignidad humana deriva el propio derecho a la intimidad.

Una cosa es declarar derechos subjetivos y otra muy distinta que el Estado se quede sin recursos para corregir las actuaciones que no sólo no nos llevan al objetivo marcado sino que nos orientan en dirección contraria.

Sería de sumo interés estudiar la «ratio legis» del artículo 19.1 de la Ley Orgánica Penitenciaria y del artículo 15 del Reglamento Penitenciario; y llegar a saber si el principio celular responde no sólo a la necesidad de preservar un espacio íntimo para la persona privada de libertad o, sino también a facilitar el ámbito espacial adecuado para alcanzar la rehabilitación y reinserción social.

¿No tiene toda persona el derecho a un mínimo espacio reservado para sí y para las personas con las que decida compartir su intimidad?. Es más ¿No existe una derecho a la intimidad pasivo?, es decir ¿Estamos obligados a presenciar el proceso morboso de otro, sus actos íntimos, las visitas de sus familiares, su muerte?

Las habitaciones compartidas, las celdas compartidas deberían ser voluntarias cuando entre las personas que quieren ocuparla se haya creado un vínculo afectivo, bien de pareja, bien de amistad, bien de familia.

¿Es posible llegar a concluir, con rotundidad, que la «celda es un ámbito de intimidad para su ocupante, un espacio apto para desarrollar vida privada»? 
¿La celda individual se vincula a una calidad mínima de vida humana y a la preservación de un área de intimidad?

¿Cuál es el límite en la reducción de la intimidad para que éste derecho sea identificable, protegiéndose su contenido mínimo?

Si la intimidad queda reducida por las exigencias de las medidas de una ordenada vida en prisión, es necesario saber qué es una ordenada vida en prisión.

¿Tiene el derecho a la intimidad en su contenido mínimo la existencia de un espacio reservado sólo para la persona? 
